\title{
How many lives is equity worth? A proposal for equity adjusted years of life saved
}

\author{
Lars Lindholm, Måns Rosén, Maria Emmelin
}

\begin{abstract}
Study objective-To present a formula for equity adjusted years of life saved (EYLS). Design-A mailed questionnaire. The survey participants were given a scenario describing a trade off between a health maximisation programme and a programme that is less efficient, but eliminates social inequalities.

Setting-Swedish politicians responsible for health care in the county councils. Participants-A sample of 449 Swedish politicians responsible for health care in the county councils.

Main results-The principle of health maximisation was rejected. Under certain conditions, the Swedish politicians are prepared to sacrifice 15 of 100 preventable deaths to achieve equity. Based on the results a formula for EYLS is presented. Conclusions-An equity adjusted formula for years of life saved has been proposed, but must be developed and revised according to each country's specific conditions and value premises. In the future, such formulas could serve the purpose of incorporating explicit considerations of equity into cost effectiveness analyses. (F Epidemiol Community Health 1998;52:808-811)
\end{abstract}

The normative foundation in cost effectiveness analysis (CEA) is health maximisation. ${ }^{12}$ However, this view has been questioned and criticised, and studies published recently have shown that both politicians, those involved in medical ethics, and people in general reject this principle. $^{3-5}$ People place greater importance on equity than is reflected in CEA. In recently published articles, the question of how to mathematically incorporate equity considerations in CEA is raised. ${ }^{3}{ }^{4}$ The aim of this article is to present a method for transforming years of life saved (YLS) to equity adjusted years of life saved (EYLS).

\section{Methods}

THE CONCEPT OF SOCIAL WELFARE FUNCTION The concept of social welfare functions is extensively discussed in the literature on economics and philosophy, and to some extent also in health economics. ${ }^{4-7}$ In short, the idea is that the level of social welfare depends both on the amount of goods available and the distribution of it between the members of the society. Furthermore, a trade off between these two values is possible. As illustrated in figure 1, point $\mathrm{A}$ and $\mathrm{B}$ are rated equal despite the difference in degrees of equity and welfare. Point $\mathrm{C}$ is superior in terms of both equity and welfare and therefore represents a higher level of social welfare.

The trade off concept discussed above can also be used to measure the equity ambitions in health. A variety of interpretations of equity in health have been discussed (equal access for equal need, equity as choice, etc), as it is far from self evident in what respect equity is worth striving for. However, the definition used in this study is equity in health, as this is the official target for the Swedish health policy formulated in the Swedish Health Act of 1983.

A parallel can be drawn to the time trade off method with an aim to estimate the weights of quality adjusted life years (QALY). ${ }^{8}$ It is assumed that $\mathrm{X}$ years of full health can have the same value as Y years of less than full health. Full health is regarded as a reference state and is arbitrarily assigned the QALY weight 1 . The respondent is then asked for the number of years in the state with not full health $(\mathrm{Y})$ that is equivalent to $\mathrm{X}$ years in full years.

The same kind of solution is possible in the trade off between equity and efficiency. Assume a programme $\mathrm{A}$ that has a known expected effect and results in an unequal distribution of health. Compare this with another programme $B$ that is expected to have a smaller effect than A, but leads to an equal distribution of health. Assign arbitrarily the equity weight 1 to programme $\mathrm{B}$ that leads to an equal distribution. It is reasonable to assume that a larger capacity to produce health effects in programme A in some people's judgement can compensate for the unequal distribution, and we can then also solve the equity weight for $\mathrm{A}$, if $\mathrm{A}$ and $\mathrm{B}$ is judged to have the same values. The reasoning can be formalised:

$$
\begin{aligned}
& \mathrm{V}\left(\mathrm{P}_{\mathrm{A}}\right)=\mathrm{V}\left(\mathrm{P}_{\mathrm{B}}\right) \\
& \mathrm{HEP}_{\mathrm{A}}>\mathrm{HEP}_{\mathrm{B}} \\
& \mathrm{E}=\mathrm{HEP}_{\mathrm{B}} / \mathrm{HEP}_{\mathrm{A}} \\
& \mathrm{E} \times \mathrm{HEP}_{\mathrm{A}}=1 \times \mathrm{HEP}_{\mathrm{B}}
\end{aligned}
$$

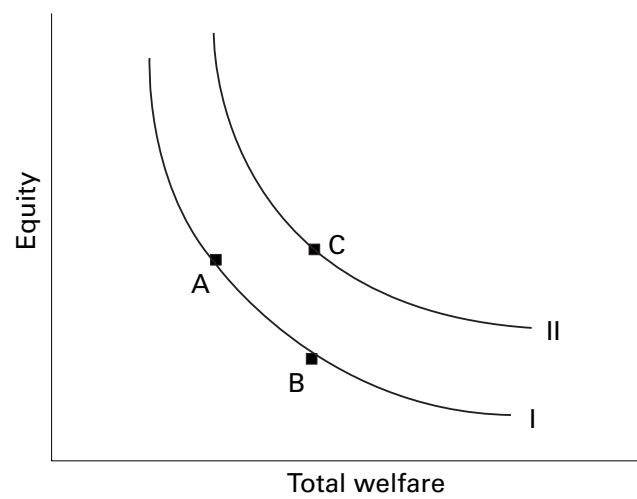

Figure 1 The concept of the social welfare function. 
Table 1 Construction of the intervention scenarios. Mortality in myocardial infarction among equally large groups of blue collar workers $(B C W)$ and white collar workers (WCW)

\begin{tabular}{|c|c|c|c|c|c|c|c|c|}
\hline \multirow[b]{2}{*}{ Intervention programmes } & \multicolumn{3}{|c|}{ Prevented deaths } & \multicolumn{3}{|c|}{$\begin{array}{l}\text { Yearly mortality after the } \\
\text { intervention }\end{array}$} & \multirow{2}{*}{$\begin{array}{l}\text { Number of } \\
\text { forgone live }\end{array}$} & \multirow{2}{*}{$\begin{array}{l}\text { Received by } \\
\text { number of } \\
\text { respondents }\end{array}$} \\
\hline & $B C W$ & $W C W$ & Total & $B C W$ & $W C W$ & Total & & \\
\hline Health maximisation & 60 & 40 & 100 & 90 & 60 & 150 & 0 & all \\
\hline Equity version $\mathrm{A}$ & 70 & 20 & 90 & 80 & 80 & 160 & 10 & $1 / 3$ \\
\hline Equity version $B$ & 65 & 15 & 80 & 85 & 85 & 170 & 20 & $1 / 3$ \\
\hline Equity version $\mathrm{C}$ & 60 & 10 & 70 & 90 & 90 & 180 & 30 & $1 / 3$ \\
\hline
\end{tabular}

Where $\mathrm{V}$ are values of $\mathrm{A}$ and $\mathrm{B}$ respectively, $\mathrm{HE}$ are the health effects per number of population in programmes $\mathrm{A}$ and $\mathrm{B}$ and $\mathrm{E}$ and 1 are equity weights.

Some people regard equity in health as the most important societal target, and thus they are willing to sacrifice health effects in exchange for increased equity. Other people regard the distribution as irrelevant and consequently judge $\mathrm{A}$ and $\mathrm{B}$ as of equal value only if the health effects are identical. The ratio between health effects per number of population in $\mathrm{A}$ and $\mathrm{B}$ can be interpreted as a measure of inequity aversion, earlier used in the discussion about social welfare functions ${ }^{910}$ and recently in the context of health policies. ${ }^{4}$ If the ratio between $\mathrm{A}$ and $\mathrm{B}$ is equal to 1 , we can say that inequity aversion is lacking. Only the amount of health effects then determine the value of the programmes. The smaller the ratio is, the more pronounced is the inequity aversion.

Inequity aversion (E) is defined as the ratio between health effects per number of population for $\mathrm{A}$ and $\mathrm{B}$.

\section{SUBJECTS}

Ten of the 24 local authorities (counties) responsible for health care in Sweden were selected, representing both the north and south of the country, as well as rural and urban areas. From each of the selected counties we received a complete list of all politicians of committees with a responsibility for health care. A mailed questionnaire was sent to this representative sample of 631 politically elected citizens in Sweden, which means that approximately $40 \%$ of all politicians responsible for health care in Sweden were included in the sample. The overall response rate was $71 \%(n=449)$ and there were no significant differences in response rates between different sub groups. The basic results from this survey is used in the following to calculate equity adjusted years of life saved (EYLS).

SURVEY INSTRUMENTS

The survey participants were given a scenario characterised by a $50 \%$ higher death rate in myocardial infarction among blue collar work-

Table 2 The value of the equity measure (E) for different interventions and respondents preferences

\begin{tabular}{llll}
\hline \multirow{4}{*}{$\begin{array}{l}\text { Choice between health } \\
\text { maximisation and }\end{array}$} & Health maximisation & Equity $(A, B$ or $C)$ & $\begin{array}{l}\text { fudge them to be of equal } \\
\text { value }\end{array}$ \\
\cline { 2 - 4 } & $0.9<\mathrm{E}<1$ & $\mathrm{E}<0.9$ & $\mathrm{E}=0.9$ \\
Equity A & $0.8<\mathrm{E}<1$ & $\mathrm{E}<0.8$ & $\mathrm{E}=0.8$ \\
Equity B & $0.7<\mathrm{E}<1$ & $\mathrm{E}<0.7$ & $\mathrm{E}=0.7$ \\
Equity C & & & \\
\hline
\end{tabular}

ers than among white collar workers, the groups being of the same size. An intervention programme "health maximisation" is more effective (prevents 100 deaths) but does not eliminate the inequality while the other alternatives "equity A" (which prevents 90 deaths), "equity B" ( 80 deaths), and "equity C" (70 deaths) are less effective but eliminate inequality. All the respondents received the programme "health maximisation" and one version of the three "equity" alternatives (A, B or C). The politicians were randomly assigned to receive one of the equity programmes $\mathrm{A}, \mathrm{B}$ or C. Costs for the different options were taken to be the same. The participants could give priority to the most effective programme health maximisation or to the one of the equitable programmes (A, B or C) they received or judge them to be of equal value (table 1 ).

The study covered three levels of gradually increasing sacrifices $(10,20,30$ lives). Imagine now a fourth equitable programme $D$, which prevents 60 deaths (sacrifice 40 lives). After the realisation of "equity D", the mortality is 95 in both groups. From an ethical point of view it is difficult to defend programme $\mathrm{D}$ in preference to health maximisation because mortality is higher in both groups for this alternative. Therefore, it seems reasonable to restrict the magnitude of $\mathrm{E}$ in this scenario to something between 1 and 0.7 .

The survey construction makes it possible to estimate the value of the E measure. If the programme "equity A" was judged to have the same value as the health maximisation programme, 100 prevented deaths should be judged equal to 90 , that is, $E=0.90$. Under equivalent assumptions the value of the $\mathrm{E}$ measure is 0.80 in version $B$ and 0.70 in version $C$ (table 2). If the respondents prefer the programme health maximisation instead of the equitable version $\mathrm{A}$, the value of the $\mathrm{E}$ measure ranges from greater than 0.9 up to 1 and if they prefer programme "equity $\mathrm{A}$ ", $\mathrm{E}$ is less than 0.9 , etc.

\section{Results}

The option "equal" gives the most exact estimation, but in practice very few people chose this option. We therefore merged the options "equal" and "prefer equity A, B or C". Accordingly, we have a sequence of proportions voting for the "equity alternative" and the proportion decreases when the number of foregone cases increase. All the respondents have $\mathrm{E}<=1$ while none have $\mathrm{E}<0.7$. Between the two ends remaining point estimates $(0.9<\mathrm{E}<=1$, etc $)$ can be placed, and a simple linear interpolation gives the empirical survival 
Table 3 Response frequencies

\begin{tabular}{llllll}
\hline & \multicolumn{2}{l}{$\begin{array}{l}\text { Prefer "equity programmes or consider } \\
\text { them to be of equal value" }\end{array}$} & & \multicolumn{2}{l}{ Prefer "health maximisation" } \\
\cline { 2 - 3 } \cline { 5 - 6 } Foregone cases & Number (\%) & Corresponds to E value & & Number (\%) & Corresponds to E value \\
\hline 10 & $82(58)$ & $0.9 \geqslant \mathrm{E} \geqslant 0.7$ & & $60(42)$ & $0.9>\mathrm{E} \geqslant 1$ \\
20 & $71(47)$ & $0.8 \geqslant \mathrm{E} \geqslant 0.7$ & & $80(53)$ & $0.8>\mathrm{E} \geqslant 1$ \\
30 & $59(42)$ & $0.7=\mathrm{E}$ & $83(58)$ & $0.7>\mathrm{E} \geqslant 1$ \\
\hline
\end{tabular}

function. The median corresponds to an $\mathrm{E}$ dividing the population into two equal parts. Median can also be estimated as the area under the curve. The calculation of mean presumes an equal distribution of answers in the whole interval. We do not know, however, if this condition is met.

The results showed that $42 \%$ of the politicians preferred health maximisation in favour of the equitable programme A (10 forgone lives). When sacrifices increased more and more politicians were in favour of health maximisation, 53\% and 58\% favoured health maximisation instead of programme B (20 forgone lives) and programme C (30 forgone lives) respectively.

As shown in table 3, $42 \%$ judge $\mathrm{E}$ to be equal to 0.7 while $47 \%$ judge $\mathrm{E}$ to be smaller or equal to 0.8 . In the next step (30 foregone cases) the median is overstepped because $58 \%$ have judged $\mathrm{E}$ to be equal to or smaller than 0.9. Accordingly, the median is between 0.8 and 0.9 , and an approximate estimation is 0.85 .

FORMULA FOR EQUITY ADJUSTED YEARS OF LIFE SAVED

Based on the derived $\mathrm{E}$ factor, a formula for EYLS can be found. We propose the following formula:

EYLS $=$ YLS $(E+(1-E) g)=$

YLS $\left(\mathrm{E}+(1-\mathrm{E})\left(\mathrm{RR}_{0}-\mathrm{RR}_{1}\right) /\left(\mathrm{RR}_{0}-1\right)\right.$

where

EYLS equity adjusted years of life saved

YLS years of life saved

$\mathrm{E}$ a measure of inequity aversion in society. If $\mathrm{E}=1$ society lacks inequity aversion and if $\mathrm{E}<1$ inequity aversion would be at hand

$1-\mathrm{E}$ the weight society attaches to equity in health

$\mathrm{g}$ degree of equity attainment, where $\mathrm{g}=1$ is full attainment

$\mathrm{RR}_{0}$ Relative risk between the two groups under study (in this case blue and white collar workers) before the intervention

$\mathrm{RR}_{1}$ Relative risk between the two groups under study after the intervention

Different interventions will be more or less successful in attaining equity and the degree of equity attainment $(\mathrm{g})$ are given by the formula $\left(R_{0}-R_{1}\right) /\left(R_{0}-1\right)$. If you reduce the $R R$ between blue and white collar workers from 1.5 before the intervention to 1.25 after the intervention you have achieved a $50 \%$ degree of goal attainment.

A hypothetical example may illustrate the potential application of EYLS. Assume programme $\mathrm{A}$ and $\mathrm{B}$ with the effects $\mathrm{YLS}_{\mathrm{A}}=100$ and $\mathrm{YLS}_{\mathrm{B}}=90$. According to our survey $\mathrm{E}$ is estimated at 0.85 and the degrees of goal attainment is $\mathrm{g}_{\mathrm{A}}=0.1$ and $\mathrm{g}_{\mathrm{B}}=0.9$ respectively. Then
KEY POINTS

- Swedish politicians reject the hypothesis that resources should be allocated according to health maximisation only.

- There is a trade off between efficiency and equity.

- Under certain conditions, the Swedish politicians are prepared to sacrifice 15 of 100 preventable deaths to achieve equity.

- A trade off formula for EYLS must be developed and revised according to each countries specific conditions and value premises.

EYLS $_{\mathrm{A}}=100(0.85+(1-0.85) 0.1)=86.5$ $\mathrm{EYLS}_{\mathrm{B}}=90(0.85+(1-0.85) 0.9)=88.65$

In this hypothetical example the priorities between programme $\mathrm{A}$ and $\mathrm{B}$ changed as a consequence of considerations of equity in years of life saved.

\section{Discussion}

The result of this first attempt to measure the value of equity shows that Swedish politicians do not accept health maximisation as the only decision criterion. They are, under certain conditions, prepared to sacrifice 15 of 100 lives to increase equity. However, the inclusion of equity and EYLS in CEA seems from our examples to have a limited impact on the results. It is only when the cost effectiveness ratio between two programmes is quite close or when the equity attainment differs substantially that priorities can change as a result of equity considerations being included in the analysis.

There are several limitations with this attempt to quantify the value politicians put on equity. The scenarios given to the respondents must be specific for a certain area and cannot present all possible outcomes. The scenario presented dealt with cardiovascular disease and blue and white collar workers respectively. We do not know if the politicians would have made the same preferences concerning cancer or between men and women, black and white or children and adults. The results are certainly also influenced by wording, that we used a mail questionnaire instead of interviews, etc. The fact that politicians and not ordinary citizens have answered the questionnaire may have influenced the results towards a stronger inequity aversion. However, also among students in a school of economics a rather strong inequity aversion was found. ${ }^{7}$

Furthermore, the results in this study were estimated in a situation were the relative risk was 1.5 . If the relative risk was much greater, one could expect a smaller E. A more general model would require further empirical studies under different conditions such as relatively small and large inequity.

A model that claims general applicability is described in a recent report from the UN. ${ }^{11}$ It is a model for equity adjusting general welfare achievements such as increased literacy or decreased mortality. In similarity with the proposal in this paper, the inequity aversion is 
measured as the ratio between an equal distribution and an unequal distribution with a larger mean along the lines proposed by Atkinson. ${ }^{9}$ The UNDP model has a macro perspective and can be used for comparisons between countries or over time, or both.

One problem with very general models is the empirical testing. The measurement of people's willingness to forego some kind of goods or achievements in exchange for equity must be undertaken in some specified context. As discussed above, this context is probably important as are certainly the social and cultural conditions in different countries.

$\mathrm{n}$ the other hand, the proposal in this article has a micro perspective-it would be appropriate to adjust for equity consequences in CEA of interventions against cardiovascular disease. The disadvantage with a situation specific model is the limited applicability but the advantage is the empirical base. There seems to be a need for both kinds of models, but one interesting approach would be to bring together generality and values held by people into one model. A development along those lines requires much more of empirical studies formulated in accordance with a theoretical framework- that is, the social welfare function.

It is important to emphasise that health maximisation and equity do not have to be in conflict with each other. If a programme both maximises health and increases equity, the relative efficiency of the programme will increase further when the concept of EYLS is applied.
The advantages of this attempt to formulate a mathematical formula for EYLS are that the method can be generalised and applied in different situations, and that the general public or the elected representatives of the population - that is, the politicians - have got a chance to give their priorities on equity before CEA are conducted. In that way, CEA can in the future be developed to incorporate EYLS or equity and quality adjusted life years saved (EQYLS).

1 Williams A. Cost-effectiveness analysis: is it ethical? $\mathcal{f ~ M e d}$ Ethics 1992;18:7-11.

2 Drummond MF. Allocating resources. Int $\mathcal{f}$ Technol Ass Health Care 1993;1:26-36.

3 Ubel PA, DeKay ML, Baron J, et al. Cost-effectiveness analysis in a setting of budget constraints. Is it equitable? $N$ Engl f Med 1996;334:1174-7.

4 Lindholm L, Rosén M, Emmelin M. An epidemiological approach towards measuring the trade-off between equity and efficiency in health policy. Health Policy 1996;35:20516 .

5 Nord E, Richardson J, Street A, et al. Maximizing health benefits vs egalitarianism: an Australian survey of health issues. Soc Sci Med 1995;41:1429-37.

6 Wagstaff A. QALYs and the equity-efficiency trade-off. fournal of Health Economics 1991;10: 21-41.

7 Johannesson M, Gerdtham U-G. A note on the estimation of the equity-efficiency trade-off for QALYs. Fournal of Health Economics 1996;15:359-68.

8 Drummond MF, Stoddart GL, Torrance GW. Methods for economic evaluation of health care programmes. Oxford: Oxford Medical, 1987.

9 Atkinson $\mathrm{AB}$. On the measurement of inequality. Fournal of Economic Theory 1970;2:244-63.

10 Layard PRG, Walters AA. Microeconomic theory. Singapore: McGraw-Hil, 1988.

11 UNDP. United Nations Development Programme. Human development Report 1995. New York: Oxford University Press, 1995. 